\title{
FRANCISCO LAPORTA, LIBORIO HIERRO Y LOS PRINCIPIOS JURÍDICOS
}

\author{
Josep Aguiló Regla \\ Universidad de Alicante
}

\section{UNA AMBIGÜEDAD MUY «SUYA»}

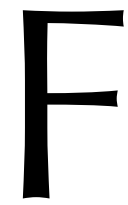

rancisco LAPORTA y Liborio HIERRO son probablemente los dos autores de teoría del Derecho en lengua española que más y mejor han escrito en defensa del imperio de la ley. Su defensa ha sido rica y valorativamente comprometida. Así, LAPORTA ha insistido en sostener que el concepto de «Estado de Derecho» no es solo un concepto descriptivo-clasificatorio, es también - y de manera muy relevante- un concepto valorativo. El Estado de Derecho no nace - sostiene - de la simple juridicidad. Si así fuera, todo Estado moderno sería un Estado de Derecho, pues ningún Estado puede prescindir del Derecho (la ley) como instrumento. Es, pues, un concepto normativo cuya función no es describir una mera propiedad del Derecho moderno. Es un concepto normativo/valorativo, resultado de la asunción de ciertas exigencias ético/políticas, que sirve para evaluar los diferentes sistemas jurídicos positivos. En el Estado de Derecho como imperio de la ley lo relevante es, en consecuencia, el compromiso moral de hacer de la ley (y de su correcta aplicación) el elemento central de la garantía de la autonomía y/o la libertad de los ciudadanos. Por su parte, Liborio HIERRO no solo participa del planteamiento anterior sino que además lo ha vinculado con una defensa de lo que se suele conocer como positivismo ético. Escribe Liborio HIERRO: «Lo que [...] he pretendido subrayar es que la adhesión al positivismo metodológico no es solo, ni principalmente, una opción de motivaciones y consecuencias epistemológicas y/u ontológicas sino que tiene, también y principalmente, motivaciones y consecuencias axiológicas». Del carácter de estas motivaciones fue perfectamente consciente SCARPELLI: «Es verdad que la separación entre el derecho y la moral, entre el derecho y los valores a la luz de los cuales se evalúa el derecho, es esencial en el positivismo jurídico; sin embargo, es preciso ver que tal separación hunde sus raíces en un acto moral, en un acto político, en una valoración [...]. En una palabra, es la moral lo que separa el derecho de la moral, es la moral a nivel de una elección general la que separa el derecho, la ciencia y la práctica del derecho, de la moral a nivel de las elecciones particulares frente a los contenidos del derecho» ${ }^{1}$.

A partir de lo anterior y sin necesidad de matizar mucho más sus respectivas posturas, pretendo dirigir a Francisco LAPORTA y Liborio HIERRO algunas preguntas que

\footnotetext{
1 L. L. HierRo, «¿Por qué ser positivista?», en Doxa, núm. 25, 2002, 299.
} 
tienen que ver con el papel que juegan los principios jurídicos en el Derecho y en el razonamiento judicial. El propósito de las mismas es tratar de plantear una ambigüedad que, en mi opinión, recorre la obra de estos dos autores; ambigüedad que hace difícil, si no imposible, su ubicación dentro de la alternativa teórica positivismo/ post-positivismo ${ }^{2}$. ¿Cuál es esta ambigüedad? ¿En qué consiste? Por un lado, ambos autores hacen una defensa muy enfática del modelo de las reglas entendido a la manera «formalista» (sin necesidad ahora de precisar demasiado este término); pero, por otro lado, parecen tener muy claro que el valor de las reglas proviene no solo de la mera forma de las propias reglas; tiene que ver también con compromisos valorativos y/o sustantivos fuertes. La ambigüedad gira en torno a la cuestión de las relaciones entre Derecho y moral; y se concreta en la alternativa entre la tesis de la separación fuerte y la tesis del valor moral de las reglas.

\section{SOBRE LAS RELACIONES ENTRE PONDERACIÓN Y SUBSUNCIÓN}

¿Qué lugar ocupa la ponderación en relación con la subsunción? ¿Es marginal respecto de ella o, por el contrario, toda subsunción presupone ya una ponderación? La cuestión es de método: cuando un juez aplica las reglas ¿cómo «debe» entenderlas? ¿Cómo debe interpretarlas? ¿Debe tomarlas a la manera formalista, es decir, como expresión de una voluntad (de un querer) o, por el contrario, a la manera sustantivista, como expresión de una ponderación (de una valoración)? Naturalmente, la cuestión no es de hecho (el problema no es si de hecho el legislador ha ponderado o no), es - como digo- de método. Y su respuesta traza, me parece, una de las fronteras teóricas entre una concepción positivista del Derecho y otra post-positivista. La relevancia teórica de estas cuestiones es manifiesta porque su respuesta acaba afectando a todas las operaciones del método jurídico; a todas las operaciones implicadas en la idea de una «correcta aplicación del Derecho (de las reglas)». Todo aplicador de reglas con pretensiones de corrección tiene que preguntarse por la noción de «lealtad a las reglas», de «aplicación leal de las reglas»: ¿Ser leal a una regla es serlo a su expresión lingüística o serlo a la ponderación que la justifica? O la misma distinción entre casos fáciles y casos difíciles se ve afectada por la alternativa anterior: ¿la facilidad/dificultad de un caso depende esencialmente de cuestiones semánticas o de cuestiones valorativas? ¿La facilidad de un caso depende de la claridad semántica de la regla a aplicar, o de la nitidez de su justificación para el caso a resolver?

Aunque de maneras diferentes y con múltiples matices que ahora se pueden obviar, los autores post-positivistas presuponen que toda regla expresa ya una ponderación de principios (y/o de derechos) y que, por tanto, ser leal a las reglas en su aplicación consiste esencialmente en ser leal a aquello que las convierte en un instrumento dotado de un sentido protector y/o promocional de ciertos bienes. Es decir, el presupuesto más o menos compartido por todos los autores post-positivistas es que la autoridad recurre a la «forma de regla» para estabilizar la expectativa de «algo» ya considerado valioso;

2 Voy a usar esta oposición conceptual en los términos recogidos en J. AguILÓ REGLA, «Positivismo y post-positivismo. Dos paradigmas jurídicos en pocas palabras», en Doxa. Cuadernos de Filosofía del Derecho, núm. 30, 2007. 
y ese «algo» de por sí valioso no puede ser ignorado por el método jurídico. Por ello, la alternativa facilidad/dificultad de un caso proviene esencialmente de los ajustes/ desajustes entre las expectativas formales (semánticas y deónticas) y las expectativas justificativas (valorativas y de corrección). Pues bien, ¿ंcuál es la postura de nuestros autores al respecto? No lo sé o, mejor dicho, no estoy seguro. Y creo que no estoy seguro porque más allá de algunas afirmaciones retóricamente muy enfáticas no han sido suficientemente claros.

\section{SOBRE LA RESPUESTA CORRECTA Y LA TESIS DE LA DISCRECIONALIDAD JUDICIAL}

Resulta una obviedad difícilmente objetable la afirmación de que puede haber casos respecto de los cuales el Derecho establece como «permitida» más de una respuesta; esto es, casos respecto de los cuales el sistema jurídico no es unitario porque las reglas admiten más de una respuesta. Negar esta posibilidad sería tanto como ignorar todas las contribuciones que la filosofía analítica ha hecho a la comprensión de los lenguajes normativos. Por tanto, la tesis de la discrecionalidad en un nivel puramente convencional está fuera de toda duda y nadie —creo- la discute. La cuestión importante aquí es si tiene sentido o no hablar de un nivel post-convencional en el Derecho. Por decirlo de algún modo: la tesis post-convencional de la respuesta correcta tiene sentido porque se acepta que en el nivel estrictamente convencional están permitidas diversas respuestas alternativas. Lo que significa que la tesis post-convencional de la única respuesta correcta (lenguaje justificativo) presupone la concurrencia de diversas respuestas permitidas (lenguaje directivo) en el nivel convencional ${ }^{3}$.

Asumido lo anterior, hay que preguntar ahora por dos implicaciones teóricas que tiene la negación de la tesis de la respuesta correcta. En primer lugar, supondría considerar que habría que abandonar por espuria y engañosa la distinción típicamente post-convencional que opone caso fácil a caso difícil; y, en su lugar, habría que asumir que la clasificación teóricamente relevante y «no ideológica» es la típicamente convencional que opone los «casos regulados» (aquellos respecto de los cuales el sistema de reglas permite una única respuesta) y los «casos no regulados» (aquellos respecto de los cuales el sistema de reglas permite más de una respuesta). Naturalmente, tanto los casos regulados como los no regulados tienen que ser decididos, de ello no hay duda. La cuestión importante es nuevamente de método: ¿cómo deben ser abordados para poder ser resueltos los casos «no regulados»? Y ahora va la segunda implicación de la negación de la tesis de la única respuesta correcta a la que quería llegar. Para exponerla consideremos el debate que tiene lugar en el seno de un tribunal colegiado que tiene que resolver un caso «no regulado». ¿Tiene sentido generar en torno a un caso no regulado una genuina deliberación (es decir, un debate cooperativo y temático) ${ }^{4} \mathrm{o}$,

3 No puedo detenerme ahora a explicarlo, pero lo que trato de expresar recurriendo a la distinción (utilizada por HABERMAS y tomada de L. KOHLBERG) entre un nivel convencional y otro post-convencional aplicado a la comprensión de las reglas, bien podría haberlo expresado recurriendo a la distinción dworkiniana que separa entre una fase interpretativa y otra post-interpretativa en la aplicación del Derecho.

4 En otro lugar he procurado distinguir cuatro modos diferentes de debatir y vincularlos con la noción de acuerdo jurídico (decisión jurídica). Los cuatro modos son las disputas («debatir es combatir», debate 
por el contrario, solo hay espacio para enfrentar una controversia (debate conflictivo y temático)? 5 . La «cooperación» deliberativa presupone la idea de que la «cooperación» tiene que poder rendir sus frutos. ¿Y qué frutos pueden ser estos? Pues aclarar cuál es la mejor respuesta de entre las alternativas convencionalmente permitidas, es decir, cuál es la respuesta correcta.

Ilustremos lo que se acaba de decir. Conforme al diseño institucional previsto, cuando un tribunal colegiado tiene que debatir y decidir un caso «problemático» debe ocurrir algo semejante a esto: los magistrados entablan una deliberación («debatir es diagnosticar»: debate cooperativo y temático) con el fin de resolver la cuestión difícil; es decir, todos se embarcan en la tarea cooperativa de tratar de hallar la mejor respuesta posible. Si no hay acuerdo entre ellos, es decir, si no todos se adhieren a la misma solución, el diseño institucional ordena transitar de la deliberación a la controversia (a «debatir es competir»: debate conflictivo y temático) y a decidir el caso por votación. Ello queda institucionalmente reflejado en la publicación de una «sentencia mayoritaria» y de unos «votos particulares»; es decir, los diversos participantes fijan claramente sus respectivas posiciones encontradas para que la ciudadanía y/o otros órganos jurisdiccionales superiores «juzguen» la cuestión que en origen era difícil y que ahora, tras el debate y la votación, ha pasado a ser controvertida. Lo interesante de lo anterior es que la institución del voto particular o en disidencia no contradice la tesis de la única respuesta correcta, sino que más bien la presupone. La institución responde a una controversia cuyo objeto es precisamente la respuesta correcta.

\section{CINCO PÁGINAS NO DAN PARA MUCHO}

Al comienzo dije que LAPORTA y HIERRO eran portadores de una ambigüedad «muy suya». Pues bien, según la respuesta que dieran a las cuestiones aquí planteadas caerían de un lado o de otro. Si sostienen que la función de la ponderación es, en realidad, la de negar las reglas (o escaparse de ellas), que ser leal a las reglas es serlo solo a su expresión, que ciertamente no hay casos difíciles sino solo casos controvertidos, que ante un caso «no regulado» no tiene sentido la genuina deliberación porque no hay una respuesta correcta que buscar cooperativamente, entonces caerán

conflictivo y actoral), las controversias («debatir es competir», debate conflictivo y temático); las deliberaciones («debatir es diagnosticar», debate cooperativo y temático») y el debate consensual («debatir es construir», debate cooperativo y actoral). Cfr. J. Aguiló Regla, Acuerdos jurídicos y debate, México, Fontamara, en prensa.

5 Cuando en un debate temático (es decir, no actoral) se habla de conflicto y de cooperación no solo debe tenerse en cuenta el hecho de que los interlocutores tengan objetivos incompatibles (conflicto) o complementarios (cooperación), sino también la actitud abierta o cerrada con la que los sujetos se aproximan al problema (la cuestión) que es objeto de debate. Si cada interlocutor considera que el problema en cuestión tiene una respuesta fácil (y, en consecuencia, adopta una actitud cerrada en relación con el mismo), pero resulta que las respectivas respuestas son incompatibles entre sí, el debate adoptará una forma conflictiva, la de una controversia. $\mathrm{Si}$, por el contrario, todos los interlocutores consideran que la cuestión es difícil y que no tienen una respuesta clara (y, en consecuencia, todos ellos adoptan una actitud abierta), el debate en cuestión adoptará la forma cooperativa de una deliberación. Lo importante de esto, para el problema que aquí estamos abordando, radica en que quien niega la tesis de la única respuesta correcta está negando que haya una oportunidad para una genuina deliberación; solo queda espacio para la controversia. 
inevitablemente del lado positivista. Si aceptan las afirmaciones anteriores pero introducen muchos matices, seguirán instalados en la ambigüedad. Y si definitivamente las abandonan por considerarlas reduccionistas e inaceptables, habrán entrado de lleno en el post-positivismo. No hace falta explicitar qué desearía yo que ocurriera, pues muchos de sus escritos están en el origen de mi post-positivismo y del de mi entorno próximo. 